\title{
WAYS TO INCREASE SUSTAINIBILITY OF THE TRANSPORTATION SYSTEM
}

\author{
Irina Makarova* \\ Kazan Federal University, Kazan, Russia \\ Ksenia Shubenkova \\ Kazan Federal University, Kazan, Russia \\ Vadim Mavrin \\ Kazan Federal University, Kazan, Russia \\ Aleksey Boyko \\ Kazan Federal University, Kazan, Russia
}

Ways to increase safety and sustainability of the city transportation system and, particularly, public transport development, transition to vehicles using alternative fuel as well as measures to promote cycling are considered in the article. This paper presents the results of the new route network modeling and the concept of the smart-bike control system. The proposed smart-bike was developed to help untrained cyclist in the situations, when the values of his/ her physical condition as well as parameters of environment are critical. Prototype of the proposed system was tested in the laboratory environment.

Key words: Sustainability of transportation system, Public transport, Alternative fuel, Smart-bike, Control system

\section{INTRODUCTION}

The global trend of urbanization and population growth, which puts ever increasing pressure on the world's cities, leaves the cities in need to develop a sustainable way of living. One of the objectives of the sustainable cities and communities area is to make cities and human settlements inclusive, safe, resilient and sustainable. To accomplish this objective by 2030 it is planned to provide access to safe, affordable, accessible and sustainable transport systems for all, improving road safety, notably by expanding public transport, with special attention to the needs of those in vulnerable situations, women, children, people with disabilities and older persons [01]. Sustainable transport system's development is one of the Global Goals for Sustainable Development and is the priority area of work of the Pan-European Program on Transport, Environment and Health (the PEP) that is focused on safe, efficient, accessible, affordable, inclusive, green and healthy mobility and transport. In the Paris Declaration in addition to the four priority goals of the PEP the new priority goal was adopted. This goal is to integrate transport, health and environmental objectives into urban and spatial planning policies by developing capacities and frameworks for integrated urban and spatial planning in order to reduce the impact of transport on health, the environment and land use, increase energy efficiency and support green and healthy mobility and transport as well as sustainable livelihoods [02]. The planning of urban and peri-urban centers according to mixed-use and smart growth design principles must be part of a sustainable transport future. Urban development along these principles will serve to lower dependence on personal vehicles and support in the increased use of public transport systems and non-motorized transport for short distances and daily commutes [03]. "Share the Road" is a UNEP initiative, developed since 2008 with cofounder the FIA Foundation for the Automobile and Society. It brings together the environment and safety agendas in the context of urban transport in the developing world where the majority of people - those moving by foot or bicycle - are disadvantaged on the road. The overall goal is to catalyse policies in government and donor agencies for systematic investments in walking and cycling road infrastructure, linked with public transport systems [04]. 
In Russia, the safety of transport systems is the issue of the day, because number of highway fatalities up 10 thousand vehicles is higher by $10-15$ times, and up 100 thousand people is 2-4 times higher than in other countries where motorization rate is higher and the network capacity is the same. The reasons for the increasing number of road accidents lie not only in developmental lag of transport infrastructure, but also have organizational nature. Thus, Moscow roads have been designed for a 4 million vehicles maximum, while the number of registered vehicles today is about 4.5 million. This is the reason of the fact that the average vehicle speed today is 7 $\div 11 \mathrm{~km} / \mathrm{h}$ and the drivers have to spend a lot of time in traffic jams. Even the day-time lorry traffic ban in the city center could not significantly improve the situation [05]. Another problem faced by an ordinary vehicle driver is the lack of parking space in the city center. In other major Russian cities, the situation is not much better, and even youngish cities where are wide avenues are familiar with the problem of traffic jams and lack of parking space. Existing problems can be subdivided into three groups: (1) disadvantages of the policy of the industry (the low quality of the transport services), (2) disadvantages of the transport infrastructure (the lack of the necessary investments, underdevelopment of walking and cycling facilities and services) and (3) problems associated with environment (climatic and natural conditions, that reduce the attractiveness of non-motorized transport).

\section{WAYS TO INCREASE SUSTAINABILITY OF THE CITY TRANSPORTATION SYSTEM}

Sustainability of the city transportation system is usually means the effective organization that is characterized by the following:

1. Transport infrastructure provides safe and comfortable travel to all road users: to the drivers of private vehicles, to the passengers of public transport, to cyclists and pedestrians, regardless of their physical disabilities

2. Public transport provides affordable (financially and physically) services to all citizens and it is an acceptable alternative to private vehicles when their using leads to overloading of the road network

3. The way of traffic organization ensures the most efficient use of the existing road network, reduction of traffic jams and negative transportrelated impact on the environment [06].
Safety of the transportation system can be determined from the viewpoint of its impact on the quality of life. In the urban agglomerations it is determined by such environmental factors as the level of environmental pollution. This is largely due to the traffic intensity and the structure of the vehicle fleet.

Air pollution is causing around 467,000 premature deaths in Europe every year, the European Environment Agency (EEA) has warned. People in urban areas are especially at risk, with around $85 \%$ exposed to fine particulate matter (PM2.5) at levels deemed harmful by the World Health Organization (WHO). PM2.5 can cause or aggravate heart disease, asthma and lung cancer. Within the European Union (EU), more than 430,000 people died prematurely due to PM2.5 in 2013, the most recent year with figures available. According to the EEA's Air quality in Europe - 2016 report, the toxic gas nitrogen dioxide (NO2) - released by vehicles and central heating boilers - has an impact equivalent to 71,000 premature deaths a year [07]. As far as transport is one of the main source of air pollution, emissions of hotbed gases, consumption of nonrestorable resources, the household inconveniences caused by the neighborhood with a busy highway and noise [08], the number of adherents of transition to a green economy is growing, initiating the development of strategies and policy documents on sustainable development of the city transportation systems. According to the Global Status Report on Road Safety 2015 [08], moving towards more sustainable modes of transport (such as cycling and public transport) has positive effects if associated road safety impacts have been well managed. These include increased physical activity, reduced emissions and noise levels, reduced congestion and more pleasant cities. Moreover, measures to promote safe public transport and non-motorized means of transport are also in line with other global moves to fight obesity and reduce noncommunicable diseases (such as heart disease, diabetes) [03]. There are three main ways cities can innovate to make transport more sustainable without increasing journey times: (1) better land use planning, (2) making existing transport modes more efficient and (3) moving towards sustainable transport. Part of measures to ensure the sustainability of transport can be planning for urban and suburban centers in accordance with development, providing for a mixed fleet of vehicles and reasonable growth (Figure 1). 


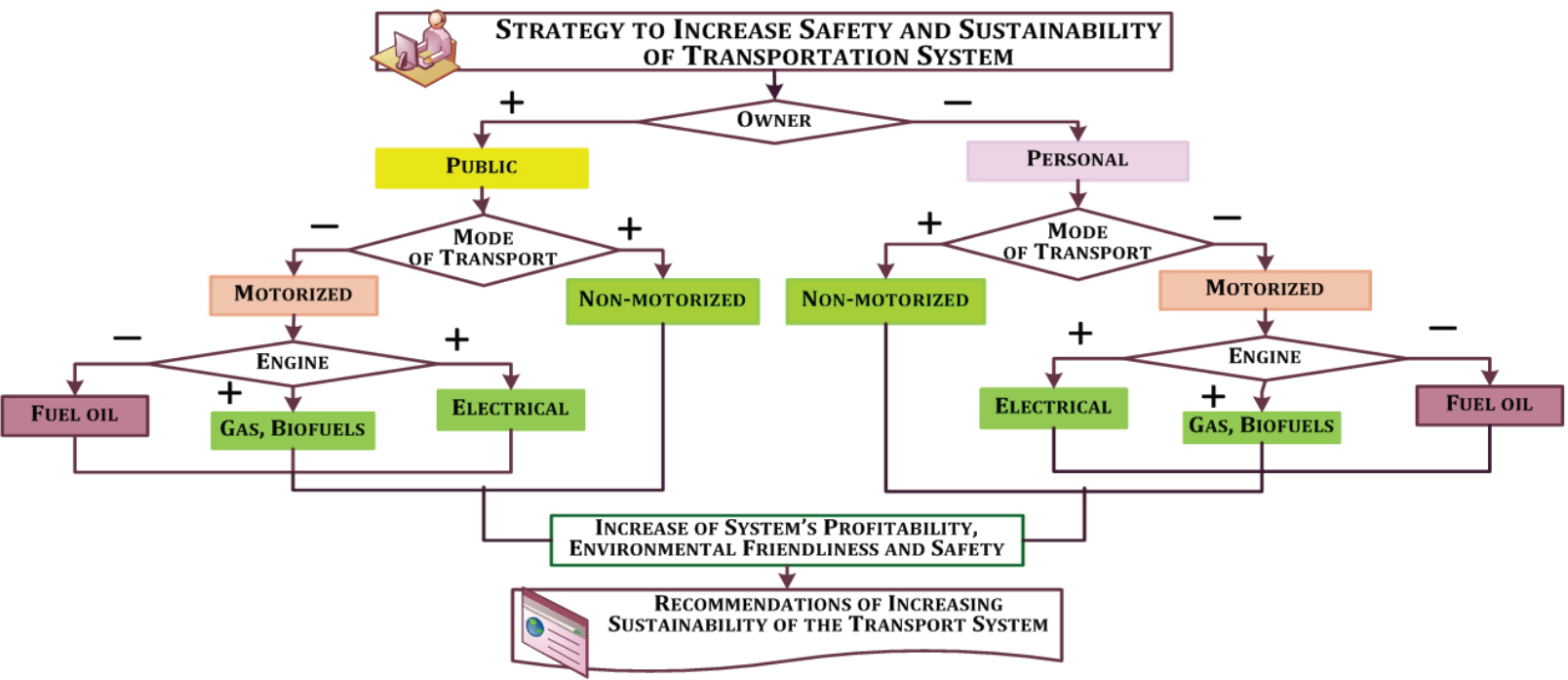

Figure 1: Ways to increase safety and sustainability of transportation system

Such principles of urban development will help to reduce dependence on private vehicles and to ensure widespread use of public and non-motorized transport for short trips and for regular commuting into the city from the suburbs [04]. The UNEP report [9] states that in order to achieve economic goals and objectives of sustainable transport development and integrated planning of its development and regulation system load, you need to switch to fuels with lower carbon content and to implement a more extensive electrification of transport.

\section{POSITIVE EXPERIENCE OF THE PUBLIC TRANSPORTATION SYSTEM'S DEVELOPMENT}

The close attention of researchers to the prospects of transport sector development is caused by a quantity of the factors either having an influence on transport system stability or able to cause serious consequences for other fields of activity. These factors require development of new methods allowing to forecast its future. Thus, the author of the research [10] uses the method of scenario analysis which allows to consider 4 variants of transport sector development. The method of scenario analysis is used by author of [11] for prediction of need for the usage of public transport. In the paper [12] the tends of introduction of technical and technological innovations are analyzed. On a basis of performed work analysis the author draws a conclusion that nowadays the process of engineering development is learned not only by specialists of technical and natural-science fields but also in economic (economic and dynamic modeling, economics, etc.) and social sciences (sociology, ecology, business management, etc.). It is noted that forecasts of transport field development are dislocated from technical-oriented point of view towards to process-oriented approach.

Safe public transportation systems are increasingly considered as an important tool to increase mobility of population, especially in the urban highly congested areas. The policy of reducing the use of personal motor transport through investments in the public transport networks development is emphasized in many high-income cities. Investments in safe public transport are also considered as a mechanism for stimulating the growth of physical activity and, therefore, strengthening the health of the population. Thus, Ahmedabad (India) in 2010 got the prize the "Sustainable transport development" for the successful implementation of the bus rapid transit (BRT) system. The point is that buses move along dedicated busways in the center of a main avenue, cyclists also have special dedicated bikeways and there are also wide sidewalks for pedestrians. This system provides significantly lower travel times and transformation of a busway corridor with severe pollution, safety problems and aesthetically displeasing into a new BRT system with significantly lower travel times, lower noise and fewer greenhouse gas emissions. Bus rapid transit in the capital of Columbia (Bogotá) that plays an important role in contributing to more sustainable mobility system, is introduced as part of wider policy package, which also included the following components: development of walkways and bikeways; such arrangements as closing main roads to motor vehicles for seven 
hours every Sunday, so that streets can be used by people for walking, cycling, jogging and meeting each other; 20 percent petrol surcharge (revenue allocated to public transport infrastructure and road maintenance); and also car-free weekday in February approved by popular vote [03].

Public transportation system's development is also connected to the search for improving its environmental and energy efficiency. In the researchs $[13,14]$ the opportunities of alternative sources of fuel for public transport are discussed. In paper [13] the economic and environmental aspects of modernization and renewal of the subsystems of public transport through the use of alternative fuels, natural gas and biodiesel fuel is analyzed. In article [15] electric cars, buses, hybrid and fuel cell (hydrogen) are compared. As a result of multifactorial expert evaluation of the alternatives it was found out that hybrid electric bus is the most suitable for Taiwan's urban areas, on short and medium routes. However, it is emphasized that at acceptable distances pure electric bus could be a better alternative. In article [16] a procedure of evaluation of efficiency of the hybrid drive Brazilian buses is proposed. The tests indicated the reduction of diesel consumption through the use of hybrid drive, which leads to lower fuel costs and carbon emissions. The article [17] is devoted to the prospects of alternative sources of energy application, including the hybrid drives for auto transport. The opportunities of hydrogen cars application are proposed in this research. In [18] the prospects of hydrogen fuel elements using in motor transport are analyzed. The authors compare the full costs cycle "from the pipe to the wheel", marking the six steps of the chain of full fuel cycle: extraction and preparation of the primary fuel, transportation of the primary fuel, reprocessing of automotive fuel, transportation of fuel to gas stations, fuel storage and conversion of automotive fuel into useful energy. The authors of research [19] upon the results of costs analyses of the conditions for transition to buses using alternative fuel of various types, come to conclusion that most important prerequisite for such a transition is the willingness of cities and bus operators to use such new technologies. The decision-maker must understand the importance of the environmental benefits of such vehicles because from economic point of view these buses are more costly. The estimation of transport effectiveness can be performed using such indicator as energy efficiency using the formula: EE in $\%=100 /$ (fuel rate in $\mathrm{kg} / \mathrm{KWh}^{*} \mathrm{~h}$ * fuel calorific value (specific heat of combustion) in $\mathrm{kWh}{ }^{*} \mathrm{~h} / \mathrm{kg}$ ). At that this indicator may be regulated by the state [20].

\section{WORLD EXPERIENCE OF USING NON-MOTORIZED MEANS OF TRANSPORT}

Considering the fact, that the world community has set an objective to reduce the levels of greenhouse gases (first of all carbon dioxide) by $50 \%$ by 2050 [04], bicycles get an additional advantage, as they do not produce $\mathrm{CO}_{2}$ emissions. Furthermore, bicycling makes efficient use of roadway capacity and reduces congestion. The advantages of cycling include cheap infrastructure requirements and improvements in public health. Bicycle pathways, lanes and parking require less space than their automobile counterparts. Cycling has direct health benefits. It is an aerobic exercise that can minimize the risk of muscle and ligament injury, lower blood pressure and reduce the risk of heart disease) [21]. Moreover, in urban areas, cycling can sometimes prove to be faster than other transport modes and also allows cyclists to avoid traffic jams. Thus, bicycling is a low-polluting and a low-cost transportation alternative and can be an important mean for getting to destinations that are not serviced by transit [22]. But at the same time cycling has a number of disadvantages, however, including a greater physical effort, the difficulty of carrying loads while cycling, being at the mercy of the weather, and, outside urban areas, travelling more slowly than motorized transport. Factors such as physical effort and speed also limit the distance that a cyclist can travel [23].

Today, in some European cities - such as Amsterdam or Copenhagen - two-thirds of all road users are cyclists. In other words, it is perfectly feasible for a majority in a metropolis to ride a bike and not travel by car. Not everybody can ride a bike every day, however, which is why the bike should not be seen as a competitor, but rather as complementary to public transport. Especially on the way to and from work there is a lot of potential: in London around 2.5 percent of all commutes to work are by bike, in Berlin 13 percent, in Munich 15 percent and in Copenhagen and Amsterdam a whopping 36 and 37 percent respectively. Such a high percentage of number of trips to work or education by bicycles in Copenhagen is provided by the fact that the priority strategy of politicians is development of 
bicycles infrastructure as a way to create more friendly city living condition [24]. The so-called "carbon footprint" of Copenhagen is one of the smallest in the world (it is less than two tonnes per capita). But there is even more ambitious goal to become neutral on emissions has been set in its development strategy. To do this there have been set very strict targets in order to follow energy efficiency standards, "green" construction and "green" energy. The city government approved the project of equipping bicycles with special sensors that report on the level of pollution and traffic congestion in real time [25]. One of the most popular counter-argument about cycling are adverse climatic and natural conditions. However, it is a matter of attitude and priority for cycle paths when clearing snow. This is confirmed by the example of Oulu, where a substantial proportion of people commute by bicycle, even when the temperature is below zero in deepest winter. This is ensured by $845 \mathrm{~km}$ of routes ( $4.3 \mathrm{~m}$ per inhabitant), $98 \%$ of which are maintained throughout winter because main route maintenance priorised over driveways. Routes parallel to driveways are separated with a green lane, which also serves as snow buildup space. There are underpasses in most busy crossings and you can reach every place by bike using cycling routes [26]. Also, technology can be used not only to make better cars but also better cycle paths, such as the proposed airconditioned bike path in Qatar [27]. Introducing bicycle lanes is not enough to make a city attuned to cyclists' needs. Essential infrastructure in a city with the size and traffic volume of Moscow includes a strategy for secure parking lots and allowing for alternative ownership structures through a bike share system. Moscow decided to introduce various parking facilities appropriate for short-term and long-term parking and to introduce a bike sharing system similar to schemes in London, Barcelona and Paris [28]. To use such a system you need to register and receive a personalized card. In Barcelona, you can rent a bike and leave it at any convenient point of the city, because there are bicycle parkings all over the major streets. An extensive network of bicycle paths and cycling facilities and services are also contributes to the development of this system [25]. Problem of the environmental pollution is a major issue in China with its notoriously poor air quality in large cities. Probably, this was the main reason of China's bicycle development [27]. In
2014 Lanzhou (Northwest China) was praised for integration Asia's second-largest bus rapid transit system with a bike share system $(14,000$ docks planned), bike parking, and greenways [29]. Bike share system is also implemented in such cities as Beijing, Zhuzhou, Shanghai, Wuhan and Hangzhou [30], where the popularity of this mode of transport is also provided by the widespread introduction of electric bicycles that help physically untrained people to overcome steep climbs and long distances, that's why an increasing number of people choose non-motorized transport as a travel mode.

\section{RESEARCH OF THE TRANSPORT PREFERENCES OF THE POPULATION}

Addressing the issues of urban mobility ensuring that is directly related to the city transportation sustainability should be based on and taking into account the preferences of the population. Only in this case the projects will be successful, and it ensures the effectiveness of investments to transport system infrastructure. To justify the choice of the best options there are two important aspects in strategic planning. They are the adequacy and quality of the initial information on the current state of the transport system as well as the preferences of the population that is necessary for predictive models design. The best tool for the comparison of options is as imulation. One of the most objective methods to study the transport preferences of the population is a questionnaire survey, that allows to predict the most likely options of the transportation system development. These surveys should be carried out in proper structuring and data processing and also with an allowance for risks. To find out what transport modes population of Naberezhnye Chelny prefer and what are the transport problems from the consumers' point of view the questionnaire has been developed. 953 respondents, constituting the various target groups, took part in the current survey (Figure 2).

Any changes in the city transport infrastructure should take into account a great amount of factors, as well as the preferences of the population of the city. The results of the survey conducted in Naberezhnye Chelny have shown that reducing the number of trips by vehicle in favor of the public transport can be achieved by route network improving, as well as the optimization of structure of the vehicle fleet on the bus routes. 


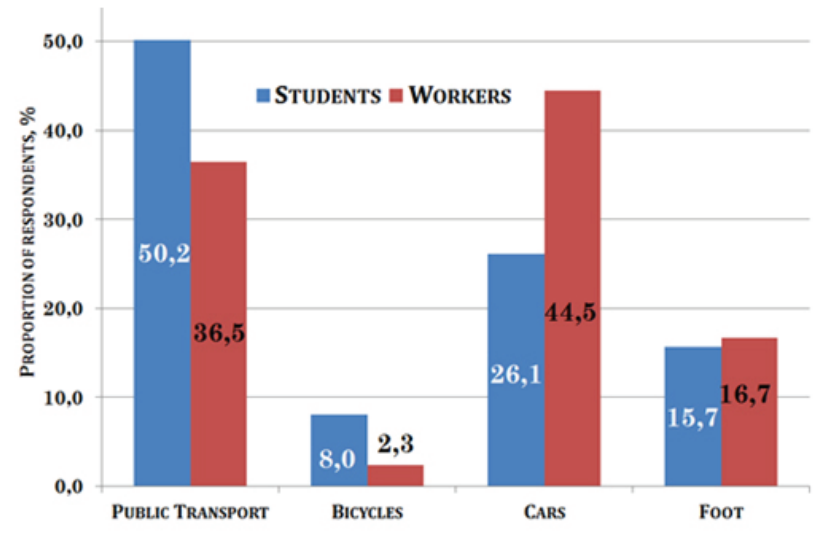

a) Number of trips to work or education

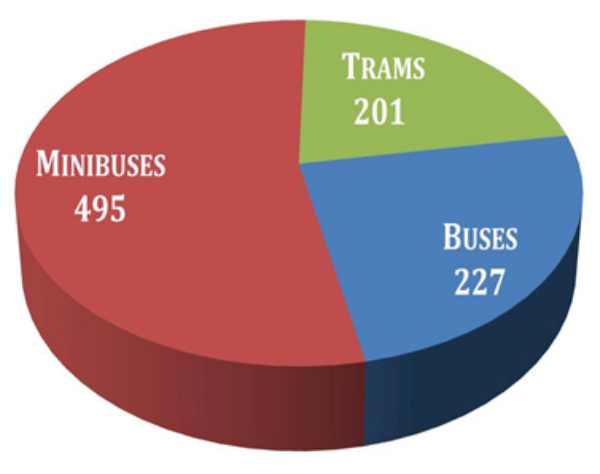

b) Travel modes preferences

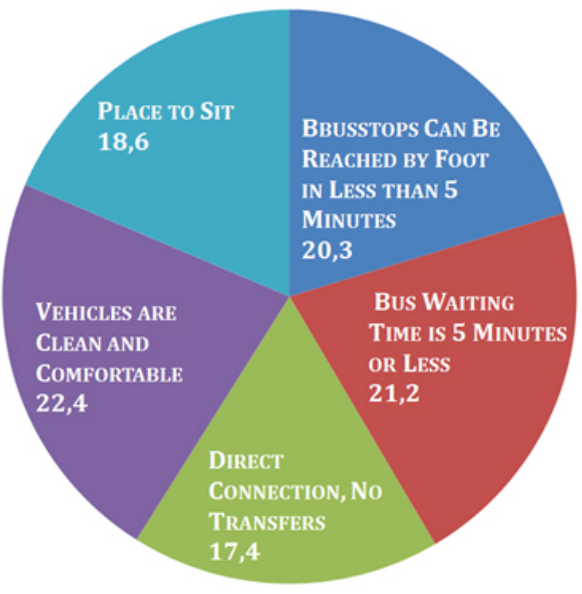

c) The number of drivers who are ready to transfer to public transport, \%

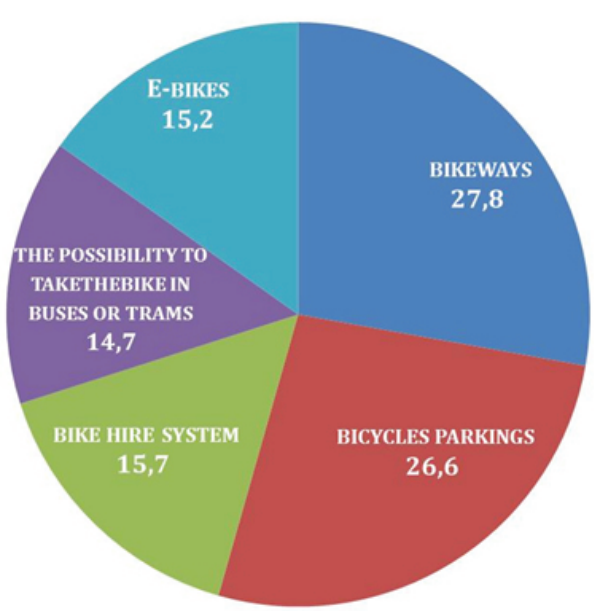

d) The number of drivers who are ready to transfer to bicycles, if there are

Figure 2: The results of the sampling survey of population of Naberezhnye Chelny

Firstly, predictive model of the new route network has been developed taking into account the following conditions: a) route network optimization should be carried out in such a way that, on the one hand, to eliminate (as far as possible) the imposition of routes, and on the other, to link all traffic areas of the city through direct routes; b) according to respondents, about $70 \%$ of drivers are willing to stop using private cars in favor of more sustainable modes of transport. That's why changes of modified trip distribution coefficients were introduced into the Travel Demand Model and the predicted values of traffic loads on the road network areas were calculated; c) while the vehicle fleet structure and the bus schedule optimization the predictive number of passengers should be taken into account. What's more it should be adjusted by changing traffic parameters. Researches made by simulation models have shown that increasing the attractiveness of the public and non-motorized modes of transport will make the traffic load almost two times lower, and improve the ecological situation in the city.

\section{RESEARCH OF THE METHODS TO INCREASE THE ATTRACTIVENESS OF PUBLIC TRANSPORT}

As optimization of the transport system can be done in two ways: regulation density of traffic flow and more environmentally friendly vehicles, for each of these areas methods to achieve their best values have been developed. So, to adjust the density of the transport stream is possible by using fiscal measures (restrictions on entry in busy areas, traffic control, etc.), as well as better use of capacity of the network (the higher occupancy rates of vehicles, replacement of more capacious and so on). Improvement of environmental performance of vehicles can be achieved through fleet renewal and replacement by a more ecological one. As it is stated in the article [31], according to the statistics, the environmental im- 
pact of large parks is higher than personal vehicles because of the large annual mileage. The personal car average mileage is 12,000 miles/ year, while the average car in park passes 23,000 miles/year. The share of new cars in the park is significant, because updating is more common than in individual owners. In addition, to stimulate the owners of parks for rational operation is easier than individual owners. Therefore, to analyze the potential benefits from fleet management subsystem of public passenger vehicles was selected (Figure 3). Research was carried out with the help of developed simulation models. One of the methods of optimization of parameters of traffic flow on this site is the improvement of the route network. The second direction is connected with your use of the bus routes greater capacity, which will reduce the density of traffic flow and reduce emissions of harmful substances. In the second stage of the optimization experiment the part of the public transport's replacement for the more environmentally friendly was done and the vehicular traffic emissions calculated for the original parameters were determined. Such replacement leads to considerable decrease in volumes of emissions of pollutants [32].

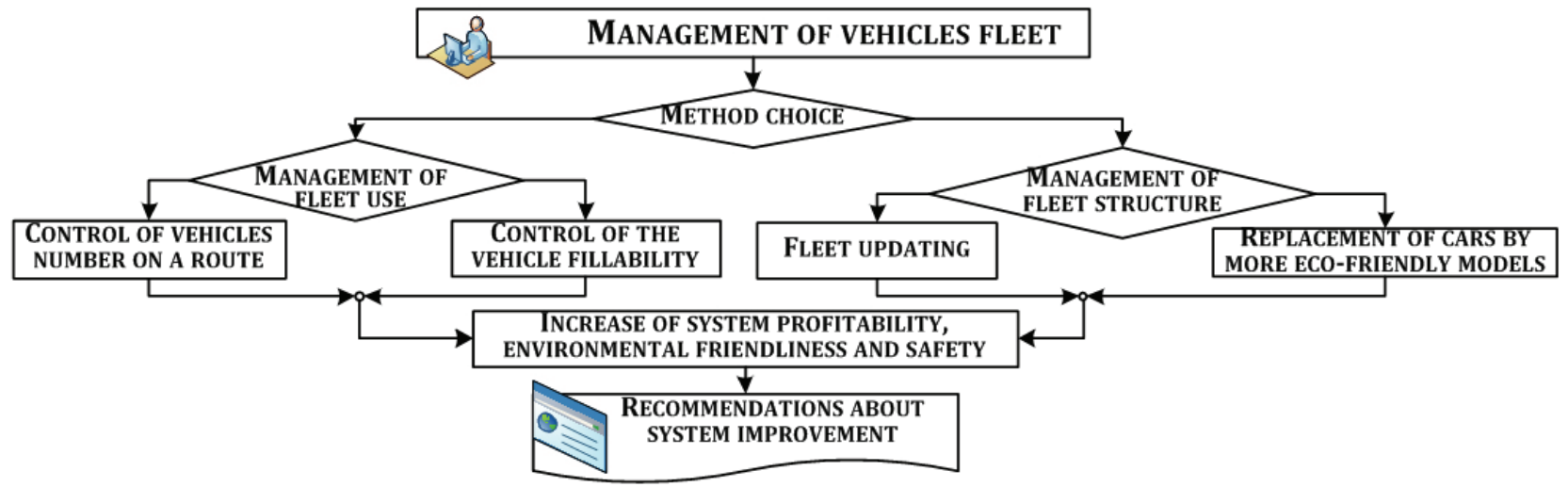

Figure 3: Methods of the vehicle fleet management

\section{SUGGESTIONS TO INCREASE THE ATTRACTIVENESS OF CYCLING}

The results of the population preferences research show that the number of people who choose bicycle as a mode of transport can be increased by the expansion of non-motorized model line-up and the integration of its infrastructure to the city road network system. What is more, cycling facilities and services should be developed. These steps, on the one hand, will help to enhance the attractiveness of bicycles for different groups of population and, on the other hand, will make roads safer and more secure particularly for non-motorized road users who are the most vulnerable. The case of Copenhagen proved that the attractiveness of cycling may be increased by the expansion of bicycles model line-up for different population groups and different use cases. In Copenhagen you can rent not only conventional bikes, but also such models as [33]:

1. The Velomobile. It protects against wind, rain and drizzle and it is best suited for long distances over $20 \mathrm{~km}$ and runs well on wide bicycle lanes outside the city and that several users would cycle more in the rain if they had a similar cycle

2. The Cargobike. It s good to transport children and to carry things and products and it is best suited for short distances below $10 \mathrm{~km}$

3. The Recumbent. It is comfortable and good to ride on, especially in headwind and it lends itself well to long distances over $20 \mathrm{~km}$

4. The Electric-assist Long John. It is good to carry cargo and children and it motivates to cycle more and drive less. It is fast, practical, fun and effortless to get around within the city

5. The Electric Bicycle. It is fun and different to drive on. The electric slide is a good help, especially uphill and against wind.

Bicycle infrastructure planning should include the creation of bike parkings, bike sheds and bikeways as well as it should be taken into account the terrain and the structure of population, who want to use the bike to get around the city. Despite a fast growing literature on the bike lanes design [34, 35, 36, 37], the problem of terrain identification and topographic conditions model- 
ing is still actual. The most common method of bicycle wayfinding is the shortest path method. As far as bicycle routing is not always possible to avoid hilly terrain, bike-lifts and electric drives creation can solve the problem of overcoming steep climbs. In contrast to the electric scooter or motorcycle, e-bike may be driven by pedals. At this time electric drive is off and accumulator is charging. E-bikes are generally different from ordinary bicycle because of three additional components presence such as an electric motor, a storage battery and a battery controller. Despite of electric drive presence electric bike is used approximately the same as an ordinary bicycle and in most countries does not require the driving license or license plate presence. Electric bicycle is suitable as a vehicle for a wide range of people with the different level of abilities, as it is easy to dose physical training. There is a number of disadvantages of electric bicycle that, makes it difficult to use. They are: significant weight (from 20 to $50 \mathrm{~kg}$ or more) and the corresponding inertia; lack of power reserve on the drive (rarely more than 25-50 km); long battery charging (usually at least 2-6 hours); short service life of lead-acid and lithium-ion storage batteries; the high cost of the final product and its use compared with an ordinary bicycle cost and use (from 2 to 10 times). One of the ways to ensure sustainable mobility in Smart Cities is the combination the possibilities of bicycles and electric transport. Electric bicycles are controlled by cycling computer (controller), which is supposed to: supply amperage from the battery to the electric motor in accordance with the user's settings; show residual battery charge on the indicator; determine the rotation / stop of pedals; limit the maximum speed of the bicycle movement in order to save energy; keep constant speed (cruise control); charge the battery while braking. At the same time there is a variety of velosimulators that are belong to the group of cardiovascular machines which are equipped to control the physical condition of a user. At the same time the main indicator to diagnose critical state is a pulse rate. As far as the parameters of the bicycle motion are influenced by both condition of the cyclist and the parameters of the environment, the rational management should be based on monitoring, analysis and on taking into account all these factors. Today there are two types of systems that are used to analyze bicycle's characteristics and motion parameters. They are (1) cycling computers - electronic devices to measure the speed and daily run of bicycle as well as such additional parameters as average speed, travel time, full speed, transmission (for multi-speed bikes), running time, temperature, atmosphere pressure, cadence (pedal rotation frequency), etc. and (2) smart phones applications - applications that duplicate functionality of cycling computer, except the ability to monitor the transmission and cadence, use built-in phone sensors such as GPS, accelerometer, barometer. To implement the smart-bike control idea it is necessary to design a system that combines cycling computer, motorized wheel (it is the type of a driving wheel, complicated mechanism, that combines the wheel itself, electric motor, power gear and braking system) and velosimulator that control the physical condition of a user. Sensors readings are transmitted into the controller for the further analysis. In critical cases (when the physical cyclist's condition is bad) the system sends the request to turn on the electric drive and after receiving the confirmation from user electric drive control is transferred to the controller. Thus, if to equip the bicycle with the universal module, which includes a pulse sensor, a controller and other components that are shown in Figure 3, and to manage it in accordance with the selected program installed on smartphone it will help to increase the attractiveness of cycling among untrained population.

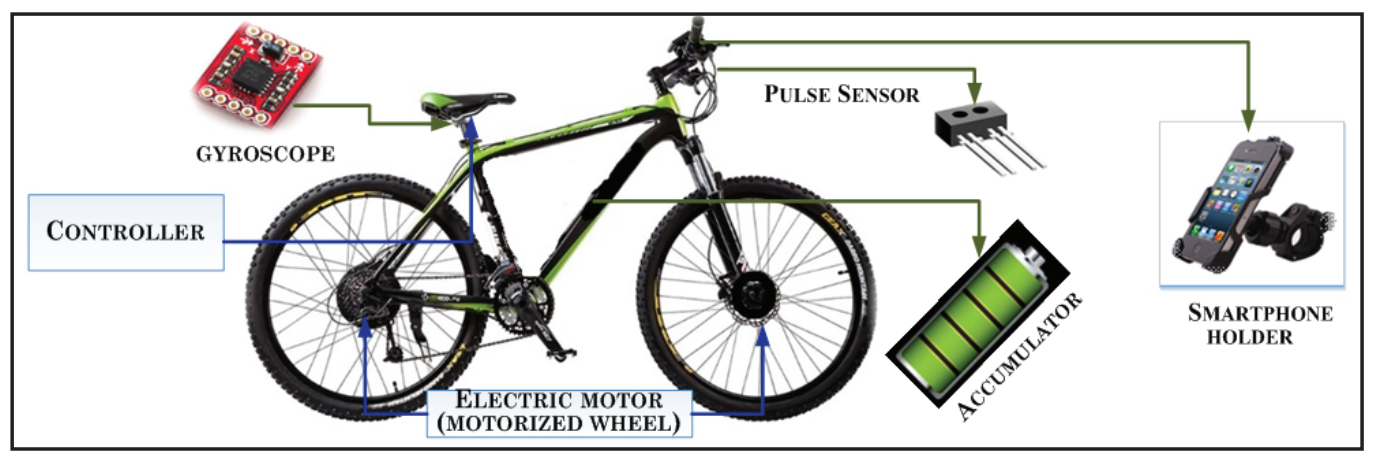

Figure 4: The elements that are included in the developed module 
Existed sensors and controllers can be used to implement the concept of smart-bike. To determine the condition of the cyclist and monitoring travel times are required means of identification of a cyclist (to set his physical characteristics in the rest condition), pulse sensor (to determine heart rate) and timer (to determine the travel time, setting training modes. To measure the parameters of the bicycle will be required gyroscope/accelerometer (to determine the position of the bicycle in the area), speedometer (to determine the travel speed), sensor of used chain sprockets and GPS sensor (for positioning, location and route setting). Module which determines the weather conditions on the route and transmits it to a smart phone is required to determine the parameters of the environment.

While designing bicycle control system it should be taken into account that the control system is completely autonomous, and the interference from the cyclist is impossible so it may be unsafe for the rider. That's why the principle of feedback between control system and a person should be implemented with the help of notifications. In this way the possibility of accidents in electric drive of bicycle false alarm cases will be excluded. Prototype of such a system was created and tested in the laboratory environment.

\section{CONCLUSIONS}

Sustainable urban mobility may be ensured by a comprehensive research of all aspects of the transportation system's operation. The most perspective ways are development of the public transportation system, more widespread usage of non-motorized transport and the effective interaction between the different transport subsystems. The effectiveness of the taken measures will depend on the quality of both technical projects and organizational and managerial decisions. Suggestions that are made in the paper allow to increase safety and effectiveness of the city transportation system and to ensure its sustainable development.

\section{REFERENCES}

1) http://www.globalgoals.org/global-goals/sustainable-cities-and-communities 2016 Nov 28.

2) https://www.unece.org/fileadmin/DAM/thepep/Publications/2015/Paris_ Declaration in_English_Final.pdf 2016 Nov 28.

3) http://unhabitat.org/books/planning-and-design-for-sustainable-urban-mobility-globalreport-on-human-settlements-2013/ 2016 Nov 28.

4) http://www.unep.org/Transport/sharetheroad/PDF/str_GlobalReport2010.pdf 2016 Nov 28.

5) Roethig, M. \& Efimenko, D. (2014). Changing urban traffic and the role of bicycles: Russian and International Experiences. U: Marcel Roethig \& Darya Efimenko (Ur.), Urban Sustainable Traffic and the Use of Bicycles, 2014-05-16, St Petersburg. Moscow: Friedrich-Ebert-Stiftung.

6) http://documents.worldbank.org/curated/ en/534831468307481001/pdf/ 732280REVISED000LogoOurbantrans0eng.pdf 2016 Nov 28.

7) http://www.eea.europa.eu/publications/airquality-in-europe-2016\#tab-figures-used 2016 Nov 28.

8) http://www.who.int/violence_injury_prevention/road_safety_status/2015/GSRRS2015 Summary_EN_final.pdf 2016 Nov 28.

9) http://www.unep.org/pdf/GGND_Final_Report.pdf 2016 Nov 28.

10) Ubbels, B. \& Rodenburg, C. \& Nijkamp, P. (2003). A multi-layer scenario analysis for sustainable international transport. Transportation Planning and Technology, 26 (1), 69-103.

11) Geurs, K. \& Wee, B.V. (2000). Backcasting as a Tool to Develop a Sustainable Transport Scenario Assuming Emission Reductions of 80-90\%. Innovation: The European Journal of Social Science Research, 13 (1), 47-62.

12) Geerlings, H. \& Lohuis, J. \& Wiegmans, B. \& et.al. (2009). A renaissance in understanding technology dynamics. The emerging concept of transition management in transportation. Transportation Planning and Technology, 32 (5), 401-422. 
13) Tzeng, G-H. \& Lin, C-W. \& Opricovic, S. (2005). Multi-criteria analysis of alternativefuel buses for public transportation. Energy Policy, 33, 1373-1383.

14) Petrović, J. \& Ivković, I. \& Vujačić, I. \& et.al. (2009). Possibilities of buses on alternative fuel in public urban transport in Belgrade. Technological and economic development of economy, 15 (1), 78-89.

15) Khan, M.M. \& Prior, D. \& Islam, M. (2012). Zero-waste living with inherently sustainable technologies. U: Jordan International Chemical Engineering Conference V.

16) Ribeiro, S.K. \& D'agosto, M.D.A. (2004). Assessment of hybrid-drive bus fuel savings for brazilian urban transit. Transportation Planning and Technology, 27 (6), 483-509.

17) Romm, J. (2006). The car and fuel of the future. Energy Policy, 34 (17), 2609-2614.

18) Difiglio, C. \& Gielen, D. (2007). Hydrogen and transportation: alternative scenarios. Mitig Adapt Strat Glob Change, 12, 387-405.

19) Straten, P. \& Wiegmans, B.W. \& Schelling, A.B. (2007). Enablers and Barriers to the Adoption of Alternatively Powered Buses. Transport Reviews: A Transnational Transdisciplinary Journal, 27 (6), 679-698.

20) http://online.zakon.kz 2016 Nov 28.

21) Tsenkova, S. \& Mahalek, D. (2014). The impact of planning policies on bicycle-transit integration in Calgary, Urban. Planning and Transport Research: An Open Access Journal, 2, 126-146.

22) Handy, S. \& Xing, Y. (2011). Factors correlated with bicycle commuting: A study in six small US cities. International Journal of Sustainable Transportation, 5, 91-110.

23) Heinen, E. \& Wee, B. \& Maat, K. (2010). Commuting by Bicycle: An Overview of the Literature. Transport Reviews, 30, 59-96.

24) Bredal, F. (2014). The Case of Copenhagen, Changing urban traffic and the role of bicycles. U: Russian and International Experiences, 2014-05-16. Moscow: Friedrich-Ebert-Stiftung.24-28

25) http://city-smart.ru/info/125.html 2016 Nov 28.

26) Tahkola, P. (2014). The Case of Oulu, Changing urban traffic and the role of bicycles. U: Russian and International Experiences,
2014-05-16. Moscow: Friedrich-Ebert-Stiftung. 29-43

27) Appenzeller, M. (2014). Cycling - Past, Present and Future, Changing urban traffic and the role of bicycles. U: Russian and International Experiences, 2014-05-16. Moscow: Friedrich-Ebert-Stiftung.11-18.

28) Mityaev, A. (2014). The Case of Moscow, Changing urban traffic and the role of bicycles. U: Russian and International Experiences, 2014-05-16. Moscow: Friedrich-Ebert-Stiftung.72-79.

29) http://www.fastcoexist.com/3025399/4-cities-developing-the-worlds-best-sustainabletransport-systems 2016 Nov 28.

30) Zhang, L. \& Zhang, J. \& Duan, Z. \& Bryde, D. (2015). Sustainable bike-sharing systems: characteristics and commonalities across cases in urban China. Journal of Cleaner Production, 97, 124-133.

31) Reich, A.A. (2012). Transportation Efficiency. Strategic Planning for Energy and the Environment, 32 (2), 32-43.

32) Sładkowski, A. \& Pamuła, W. (2016). INTELLIGENT TRANSPORTATION SYSTEMS PROBLEMSANDPERSPECTIVES. Springer International Publishing. doi:10.1007/978-3319-19150-8.

33) http://www.bicycleinnovationlab.dk/activities/ data-popular-bikes?show=lgg 2016 Nov 28.

34) Parkin, J. \& Rotheram, J. (2010). Design speeds and acceleration characteristics of bicycle traffic for use in planning, design and appraisal. Transport Policy, 17, 335-341.

35) Larsen, J. \& Patterson, Z. \& El-Geneidy, A. (2013). Build It. But Where? The Use of Geographic Information Systems in Identifying Locations for New Cycling Infrastructure. International Journal of Sustainable Transportation, 7, 299-317.

36) Forsyth, A. \& Krizek, K. (2011). Urban Design: Is there a Distinctive View from the Bicycle? Journal of Urban Design, 16, 531-549.

37) Rybarczyk, G. (2014). Simulating bicycle wayfinding mechanisms in an urban environment. Urban, Planning and Transport Research: An Open Access Jou

Paper sent to revision: 12.01.2016.

Paper ready for publication: 31.01.2017. 